\title{
Commentary: Lesson one of medical school: Observe the patient before deciding the treatment
}

\author{
N. Bryce Robinson, MD, Irbaz Hameed, MD, Ajita Naik, MD, and Mario Gaudino, MD
}

From the Department of Cardiothoracic Surgery, Weill Cornell Medicine, New York, NY.

Disclosures: Authors have nothing to disclose with regard to commercial support.

Received for publication Oct 4, 2019; revisions received Oct 4, 2019; accepted for publication Oct 4, 2019; available ahead of print Oct 16, 2019.

Address for reprints: Mario Gaudino, MD, Department of Cardiothoracic Surgery, Weill Cornell Medicine, $525 \mathrm{E}$ 68th St, New York, NY 10065 (E-mail: mfg9004@med.cornell.edu).

J Thorac Cardiovasc Surg 2020;160:920-1

$0022-5223 / \$ 36.00$

Copyright (c) 2019 by The American Association for Thoracic Surgery

https://doi.org/10.1016/j.jtcvs.2019.10.025

In the current issue of the Journal, Fremes and colleagues ${ }^{1}$ compare aortic valve replacement (AVR) with aortic root enlargement to isolated AVR for early and late mortality using the Ontario Clinical and Administrative Database. Following extensive adjustment for patients' baseline characteristics, the authors found no difference in 30-day mortality between AVR + aortic root enlargement versus AVR $(2.0 \%$ vs $2.1 \%, P=1.00)$. Although the experienced Canadian group deserves, as ever, commendation for the rigorous methodology, their analysis could not adjust for key factors such as surgeon experience and, most importantly, treatment allocation bias.

An operating surgeon's decision to perform a root enlargement procedure versus isolated AVR is not random but based on careful assessment of the patient's anatomy and physiology, as well as the surgeon's expertise in the complex procedure. This is reminiscent of day one of medical school, when we are taught to tailor decisions to the individual patient. Surgeons regularly draw from their own experience to "eye-ball" patient variables when making operative decisions. While essential to clinical practice, this presents major bias when undertaking observational research.

Cardiac surgery literature presents other instances of unmeasured variables affecting treatment selection and confounding analyses. Several studies have shown outcomes of mitral valve repair to be superior to replacement. ${ }^{2}$ Mitral replacement, however, is quicker and more reproducible when compared with repair, and thus more likely to be performed in patients whose surgical risk is felt to be greater by the operating surgeon. ${ }^{3}$ Although propensity matching and multivariable analysis could have accounted for some of the measurable differences, treatment allocation bias remains an important yet difficult to measure effect. The inability to perform intention-to-treat analysis in retrospective studies further makes it is possible that the results could partly be due to intraoperative crossover from repair to replacement. The scenario is similar for single versus bilateral internal thoracic artery (BITA) grafting, where BITA

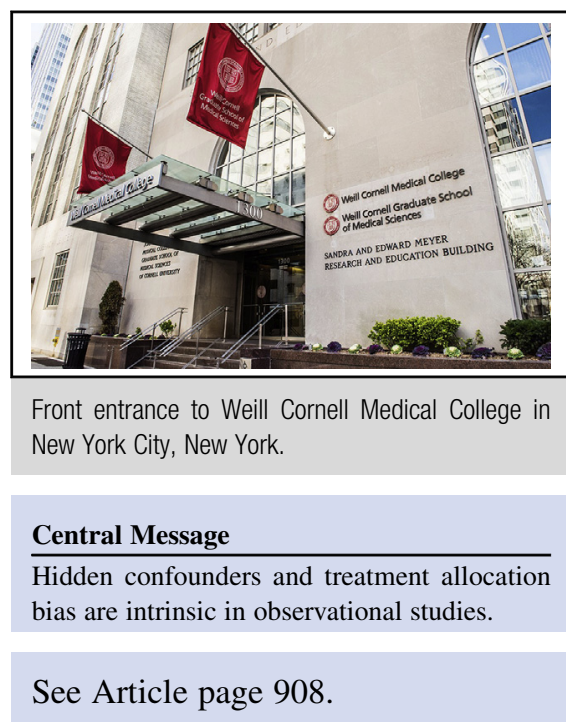

grafting has been associated with improved outcomes. ${ }^{4}$ The presence of unmeasured confounders relating to the surgeon and the patient, however, have brought into question the causality in this association and the true treatment effect of BITA. ${ }^{5}$ Surgeons likely reserve BITA grafting for healthier patients with longer life expectancy, and there can be additional bias related to the graftability and location of target vessels.

Treatment allocation is based on the individual surgeon's experience and clinical judgment, factors that are very difficult to quantify and for which to adjust. Only random assignment of sufficient samples of patients to different treatment groups can facilitate equal baseline distribution of known and unknown prognostic factors between the compared groups. Under these conditions, the perceived differences in the outcomes between the groups can be rightfully attributed to the true treatment effect. In the absence of randomized controlled trials, interpretation of observational data must take into account the most powerful hidden confounder: the surgeon's judgment. When evaluating a patient, the operating surgeon must process subjective and objective measures and decide whether an operation would be of benefit. In summary, exactly what we learn on day one of medical school.

\section{References}

1. Tam DY, Dharma C, Rocha RV, Ouzounian M, Wijeysundera HC, Austin PC, et al. Early and late outcomes following aortic root enlargement: a multicenter propensity score-matched cohort analysis. J Thorac Cardiovasc Surg. 2020;160: 908-19.e15. 
2. Thourani VH, Weintraub WS, Guyton RA, Jones EL, Williams WH, Elkabbani S, et al. Outcomes and long-term survival for patients undergoing mitral valve repair versus replacement: effect of age and concomitant coronary artery bypass grafting. Circulation. 2003;22:298-304.

3. Silaschi M, Chaubey S, Aldalati O, Khan H, Uzzaman MM, Singh M, et al. Mitral valve repair superior to mitral valve replacement in elderly patients? Comparison of short- and long-term outcomes in a propensity-matched cohort. J Am Heart Assoc. $2016 ; 28: 5$.
4. Stevens L-M, Madsen JC, Isselbacher EM, Khairy P, MacGillivray TE, Hilgenberg AD, et al. Surgical management and long-term outcomes for acute ascending aortic dissection. J Thorac Cardiovasc Surg. 2009;138: 1349-57.e1.

5. Gaudino M, Di Franco A, Rahouma M, Tam DY, Iannaccone M, Deb S, et al. Unmeasured confounders in observational studies comparing bilateral versus single internal thoracic artery for coronary artery bypass grafting: a meta-analysis. $J$ Am Heart Assoc. 2018;6:7. 